\title{
Treatment of neuropathic pain: Focus on antidepressants, opioids and gabapentin
}

\author{
C Peter N Watson MD FRCPC ${ }^{1}$, Judith H Watt-Watson RN PhD ${ }^{2}$
}

CPN Watson, JH Watt-Watson.

Treatment of neuropathic pain: Focus on antidepressants, opioids and gabapentin.

Pain Res Manage 1999;4(4):168-178.

BACKGROUND: The treatment of neuropathic pain continues to be difficult. Randomized, controlled trials (RCTs) provide some evidence to guide therapy. Most data relate to antidepressant therapy, although there is information on anticonvulsants and other treatments. Mistaken beliefs about many of these treatments are prevalent and need to be dispelled. Opioids are increasingly being used for the refractory patient. There has been recent enthusiasm for the anticonvulsant gabapentin for the treatment of these conditions.

OBJECTIVE: To review the positive scientific data that are largely confined to RCTs in two neuropathic pain conditions that have proved to be good models for clinical investigation. These models are postherpetic neuralgia and painful diabetic neuropathy. Negative RCTs, weakly positive RCTs, other types of treatments and neuropathic conditions are also examined.

METHODS: This review of the literature used MEDLINE, CINAHL and the Cochrane Database.

RESULTS: There is extensive literature supporting the use of the older generation antidepressants, such as amitriptyline, in neuropathic pain. Newer RCTs support the use of gabapentin and opioids. Other therapies may be useful in individual cases on a trial and error basis but are largely unsupported by RCTs at this time. CONCLUSIONS: First-line therapy for neuropathic pain may be either an older generation antidepressant, such as amitriptyline or nortriptyline, or the anticonvulsant gabapentin. A variety of trial and error approaches may be used, none of which has sound scientific approval. For refractory patients, chronic opioid therapy may be the only avenue of relief, and evidence is accumulating that this approach is safe if proper guidelines are observed. The possibility that some types of neuropathic pain may be prevented is exciting. Progress in the treatment of neuropathic pain has been slow but steady, and there continues to be a need to explore newer agents and approaches.

Key Words: Neuropathic pain; Pain treatment

Traitement de la douleur neurogène : Accent sur les antidépresseurs, les opiacés et la gabapentine

HISTORIQUE : Le traitement de la douleur neurogène reste complexe. Des essais randomisés contrôlés (ERC) donnent quelques indications pour orienter le traitement. La plupart des données concernent le traitement aux antidépresseurs, bien qu'il y ait aussi des données sur les traitements aux anticonvulsivants et autres. Certains préjugés à l'endroit de bon nombre de ces traitements sont fort répandus et méritent d'être combattus. Les opiacés sont de plus en plus utilisés dans ce contexte pour traiter les cas rebelles. Récemment, l'anticonvulsivant gabapentine a fait l'objet d'un intérêt soutenu pour le traitement de ce type d'affection.

OBJECTIF : Passer en revue les données scientifiques positives émanant d'essais randomisés contrôlés sur le traitement de deux types de douleur neurogène et qui se sont révélés être de bons modèles de recherche clinique. Ces modèles sont la névralgie post-zostérienne et la neuropathie diabétique. On a également étudié les ERC négatifs, les ERC faiblement positifs et autres types de traitements et de maladies neurogènes.

MÉTHODES : Cette revue de la littérature a été effectuée à partir d'une interrogation des réseaux MEDLINE et CINAHL et de la base de données Cochrane.

RÉSULTATS : La littérature abonde à l'appui de l'utilisation des antidépresseurs de génération antérieure, comme l'amitriptyline, pour soigner la douleur neurogène. Les essais cliniques randomisés contrôlés plus récents appuient l'utilisation de la gabapentine et des

voir page suivante

${ }^{1}$ Department of Medicine and ${ }^{2}$ Faculty of Nursing, University of Toronto, Toronto, Ontario

Correspondence and reprints: Dr C Peter N Watson, 89 Humber College Boulevard, Suite 104,Toronto, Ontario M9V 1B8. Telephone 416-239-3494,

fax 416-239-6365

Received for publication March 19, 1999. Accepted June 8, 1999. 
opiacés. D'autres traitements peuvent être utiles à l'essai dans certains cas, mais bénéficient peu de l'appui des ERC pour l'instant.

CONCLUSION : Le traitement de première intention de la douleur neurogène peut être soit un antidépresseur de génération antérieure, comme l'amitriptyline ou la nortriptyline, ou l'anticonvulsivant gabapentine. Divers types d'approches peuvent être mis à l'essai, mais aucun ne repose sur des preuves scientifiques. Dans les cas rebelles, le traitement prolongé aux opiacés peut être la seule façon de procurer un soulagement et les preuves s'accumulent à l'effet que cette approche est sécuritaire si l'on observe les règles qui s'imposent. La possibilité de prévenir certains types de douleurs neurogènes est intéressante. Le traitement de la douleur neurogène a évolué lentement, mais régu-
For the easing of neuro-traumatic pain we tried, in turn, the whole range of medicines known as narcotics, such as hyoscyamus, daturia, atropia, and morphia. None of them, save the last, seemed, when singly used, to be of the slightest value, and one by one they were laid aside until in the vast mass of cases the salts of morphia alone were employed. Silas Weir Mitchell 1872 (1).

A lthough the above quotation was written over a century and a quarter ago, we are only now entering an era in which opioids are gaining acceptability for the treatment of painful neuropathies and other nonmalignant pain. The present article reviews the renaissance of this treatment approach, the use of the newest agent gabapentin and the extensive literature on what has been, for some years, the standard therapy the older antidepressants. These approaches all have support from randomized, controlled trials (RCTs), mainly in treating two clinical conditions. The reader should be aware and perhaps cautioned that although this report is in part evidence based, it also reviews uncontrolled clinical data.

For the purposes of this review, neuropathic pain is defined as pain caused by injury or dysfunction in the peripheral or central nervous system (2). The term peripheral neuropathic pain is used for peripherally generated pain (nerve or nerve root), and the term central pain is applied to pain arising from the spinal cord or more rostral areas in the central nervous system. Trigeminal neuralgia (tic douloureux), although a neuropathic pain, is not discussed. It is a rather unique condition occurring only in the head, with specific and usually successful medical and surgical management to which a large amount of literature has been devoted. Also not discussed is complex regional pain syndrome (reflex sympathetic dystrophy) because it is a subject in itself. Tables 1 and 2 list some of the broad range of conditions that may be encompassed under the rubric of peripheral neuropathic and central pain, respectively.

Neuropathic pain is a common problem in patients seen by chronic pain specialists and is difficult to treat even in sophisticated hands. For many of these persistent, painful conditions there are no controlled trials, and so mistaken beliefs have arisen that need to be dispelled. Examples of incorrect beliefs are that carbamazepine is the drug of choice for lancinating and other neuropathic pain outside the head, that phenothiazines are useful adjuncts to antidepressants or as sole therapy, and that opioids are ineffective and to be avoided because of the potential for physical and psychological dependency and tolerance. We attempt to dispel these mistaken

\section{TABLE 1}

Some types of peripherally initiated neuropathic pain

Carpal tunnel syndrome
Meralgia paresthetica
Diabetic neuropathy
Alcohol/nutritional neuropathy
Acute/subacute radicular pain
$\mathrm{L}_{5} / \mathrm{S}_{1}$
$\mathrm{C}_{6} / \mathrm{C}_{7}$
Trigeminal neuralgia
Trigeminal neuropathy
Atypical facial pain
Anesthesia dolorosa
Post-traumatic neuropathy
Postherpetic neuralgia
Failed back syndrome
$\quad$ Root sleeve fibrosis
Arachnoiditis
Brachial plexus neuropathies/avulsion
Incisional neuralgia
Postmastectomy pain syndrome
Post-thoracotomy pain
Causalgia
Guillain Barré syndrome
Phantom limb pain

TABLE 2

Some types of central pain syndromes

Thalamic syndrome (stroke, tumour)

Multiple sclerosis (trigeminal neuralgia, painful tonic seizures)

Wallenberg's (lateral medullary) syndrome

Syringomyelia

Post-traumatic central pain

beliefs and clarify what medication, in our view, is most effective, based largely on scientific data. This review focuses on two peripheral neuropathic pain conditions for which there is good scientific data, postherpetic neuralgia (PHN) and painful diabetic neuropathy (PDN) (Table 3) and on the RCTs relating to central pain. We also raise the issue of whether pre-emptive or early and aggressive treatment of acute pain may prevent progression to a chronic painful state.

\section{MATERIALS AND METHODS}

MEDLINE, CINAHL and the Cochrane Database were searched for RCTs on neuropathic pain generally and on PHN and PDN specifically. A recent critical review (3) ex- 
TABLE 3

Ratings and effectiveness of clinical trials for postherpetic neuralgia and painful diabetic neuropathy

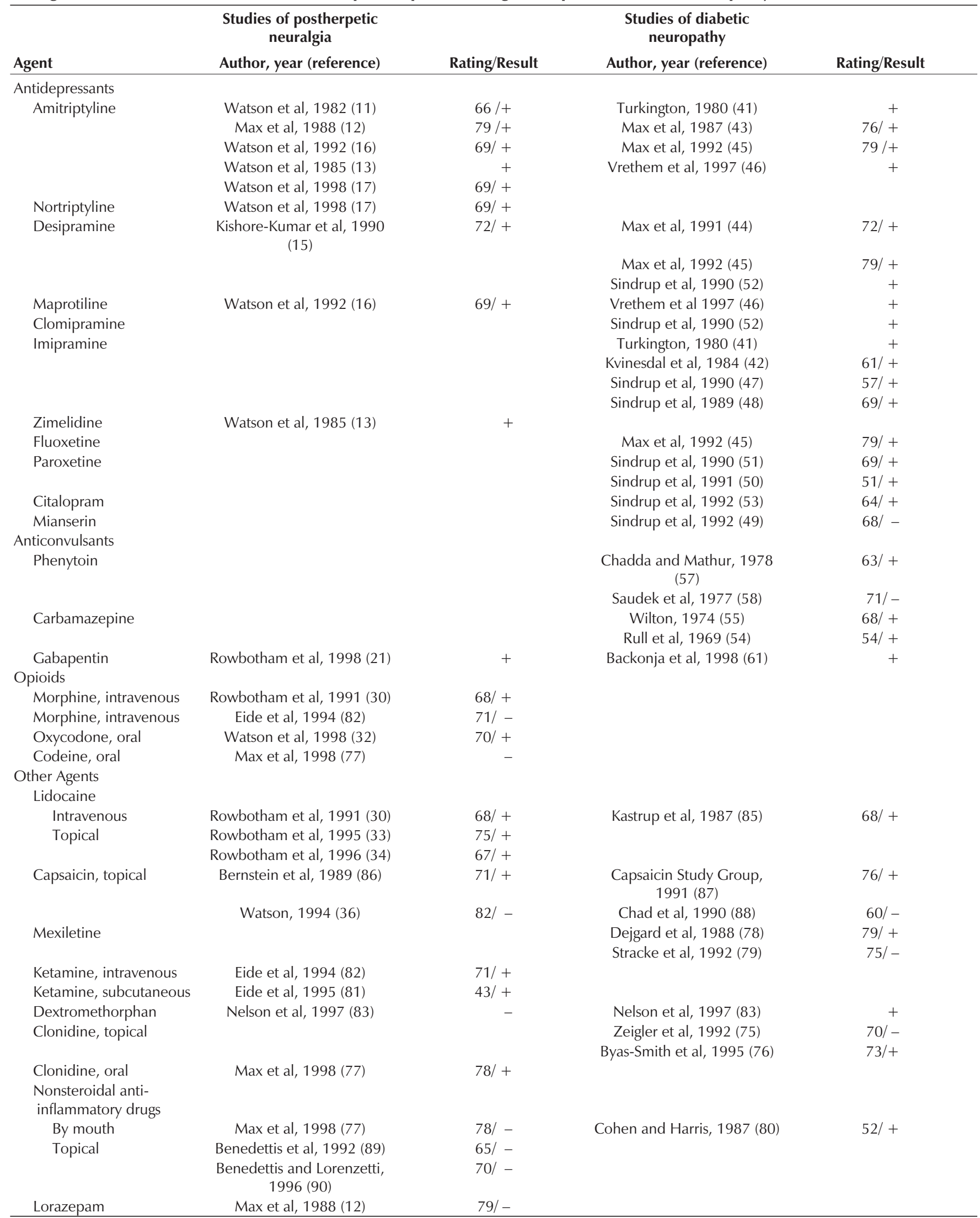

Numerical rating are from reference 3. See Table 4 for how the ratings were determined. Trials appearing twice are crossover comparisons of two drugs. + Effective; - Not effective 
TABLE 4

Scoring criteria for the evaluation of methods in controlled clinical trials for peripheral neuropathic pain from Kingery (3)

\begin{tabular}{|c|c|}
\hline Criteria & Criteria Weight \\
\hline \multicolumn{2}{|l|}{ Study population } \\
\hline Inclusion/exclusion criteria listed & 2 \\
\hline Randomized & 6 \\
\hline $\begin{array}{l}\text { Number of subjects in smallest group after } 15 \text { randomizations (three } \\
\text { points for each } 10 \text { subjects up to } 50 \text { subjects) }\end{array}$ & 15 \\
\hline \multicolumn{2}{|l|}{ No baseline difference between groups for } \\
\hline Duration of symptoms & 2 \\
\hline Outcome measures & 8 \\
\hline \multicolumn{2}{|l|}{ Patient attrition at last outcome measure } \\
\hline$<20 \%$ & 2 \\
\hline$<10 \%$ & 2 \\
\hline \multicolumn{2}{|l|}{ Interventions } \\
\hline Treatment protocol explicitly described & 3 \\
\hline Comparison with placebo treatment & 8 \\
\hline Comparison with another treatment dose or placebo with side effects & 5 \\
\hline \multicolumn{2}{|l|}{ Effect } \\
\hline \multicolumn{2}{|l|}{ Blinded patients } \\
\hline Attempted blinding & 4 \\
\hline Blinding evaluated and successful & 4 \\
\hline Blinded outcome assessment & 4 \\
\hline $\begin{array}{l}\text { Outcome measures: two points for each measure, maximum } \\
\text { score of } 10\end{array}$ & 10 \\
\hline $\begin{array}{l}\text { Longest follow-up period comparing outcome measures among groups } \\
\text { (one point for each week after onset of treatment up to } 13 \text { weeks) }\end{array}$ & 13 \\
\hline \multicolumn{2}{|l|}{ Data presentation and analysis } \\
\hline $\begin{array}{l}\text { Statistical tests for effect differences between treatment groups } \\
(\mathrm{P}<0.05)\end{array}$ & 12 \\
\hline Maximum possible score & 100 \\
\hline
\end{tabular}

amined some 50 RCTs in peripheral neuropathic pain. The purpose of the review is not to duplicate this thorough and excellent work, but rather to compare and contrast the clinical research on PHN and PDN as the primary models used in this area of clinical investigation. Publications relating to central pain and other neuropathic pain are also included. The RCTs rated by the method of Kingery (3) have their maximum potential score out of 100 listed under the rating columns in Table 3. Kingery scored the trials he received according to the criteria in Table 4. Where no ratings appear, the study was not rated by Kingery because it is not an RCT or is a more recent RCT. Uncontrolled or nonblinded data were included where no other information exists. None of the RCTs critically and favourably reviewed by Kingery fulfilled all the criteria for an ideal study as outlined in Table 4, or in the Consolidated Standards of Reporting Trials (CONSORT) statement (4). Valuable information may be found in preliminary, less rigorous investigations where no other data exist. However, all the trials discussed here were published in peer-reviewed journals, and most were rated highly in the critical review mentioned above.

\section{POSTHERPETIC NEURALGIA}

PHN is a common cause of chronic pain in the elderly population. The eruption of herpes zoster (HZ), the most common neurological illness (5), is a harbinger of persistent neuropathic pain for at least $50 \%$ of those over 60 years of age (6). Although the natural progression is one of slow improve- ment in some patients, many patients suffer for years. Our experience is that a judicious choice of medication and careful monitoring result in satisfactory control for approximately $70 \%$ of patients. About $30 \%$ of patients remain inadequately relieved or have intractable pain. The prevention of HZ by vaccination of the elderly, along with early aggressive treatment of acute zoster pain, may be crucial for this group (7).

As in other neuropathies, steady burning, or aching and paroxysmal lancinating pain may occur. These symptoms may occur spontaneously and are often aggravated by tactile contact with the involved skin such as friction from even the lightest clothing. Paradoxically, firm pressure may provide some relief.

Examination of the affected, scarred skin often reveals both a loss of sensation to pinprick, temperature and touch over a wider area than the scars, and an area of sensitive or painful skin. This sensitive area of skin may be much larger than that occupied by the scarring or anesthetic area but paradoxically may include the anesthetic areas and be elicited by a different type of stimulation (skin stroking or skin traction between thumb and forefinger). An explanation may be that these latter stimuli may cause a summation effect on hypersensitive, deafferented, central neurons with expanded receptive fields.

PHN is a particularly good model of neuropathic pain for drug trials. Patients with PHN who have pain that is fairly stable over time can be found in sufficient numbers for these studies. 
Antidepressant therapy, as opposed to many other putative therapies for this difficult problem, has an established scientific basis. Woodforde et al (8) were the first to recognize that amitriptyline could afford relief in truly chronic postherpetic pain patients. They thought that all 14 of the subjects in their open-label trial were depressed and this was the rationale for using amitriptyline. They initially used a dose of $10 \mathrm{mg}$ four times per day and this was gradually increased to $25 \mathrm{mg}$ four times per day, which achieved good pain relief in 11 patients that lasted one to 11 months.

Taub (9) reported treating successfully five sufferers of PHN of greater than three months' duration using amitriptyline combined with a phenothiazine (fluphenazine, perphenazine or thioridazine). In a later publication, Taub and Collins (10) used a daily dose of $75 \mathrm{mg}$ of amitriptyline along with fluphenazine $1 \mathrm{mg}$ three times per day in 17 patients with postherpetic pain of greater than one year's duration. Patients reported good relief in both studies, with some mild residual pain at three to six years of follow-up. Taub and Collins (10) believed that amitriptyline alone was ineffective and that it was best used to combat the depressant action of the other drugs. Subsequently, this regimen came into widespread use.

Clinical experience has convinced us that amitriptyline prescribed alone results in pain relief in PHN and that phenothiazines alone are ineffective. Most patients are not depressed except mildly in some cases as a secondary response to pain. A double-blind, placebo controlled, crossover trial of amitriptyline was conducted in 24 patients with this disorder (11). All patients had PHN of more than three months' duration, and good results were achieved in 16 of 24 (67\%). Because most patients were not depressed and reported pain relief without a change in depression ratings, the drug appeared to result in pain relief that was independent of an antidepressant effect. This analgesia occurred at lower doses (median $75 \mathrm{mg}$ ) than those usually used to treat depression. Follow-up was for a median of 12 months, with good results maintained in 12 of 22 patients (55\%). The use of small doses (10 to $25 \mathrm{mg}$ ) to start followed by small increments resulted in few significant side effects. A subsequent trial has corroborated these results (12). Amitriptyline has limitations for long term use because of side effects, and because relief is rarely complete and occurs in only about two-thirds of patients.

One action of this drug is that it potentiates both serotonin and noradrenaline in the central nervous system. These neurotransmitters are thought to be involved in pain-inhibiting systems descending from the brainstem to the dorsal horn of the spinal cord. Subsequent research has explored whether selective serotonergic or noradrenergic agents might be more effective and have fewer side effects. Our experience with serotonergic agents (clomipramine, trazodone, nefasodone, fluoxetine and zimelidine) in PHN has been disappointing $(13,14)$. The evidence supporting the use of noradrenergic agents is more compelling. Desipramine, a selective noradrenaline reuptake inhibitor, has proved to be more effective than placebo in this disease, and pain relief with this drug also has not been mediated by improvement in depression (15). Although desipramine is reported to have fewer side effects, it is not known how it compares with amitriptyline. A randomized, double-blind trial, comparing maprotiline (noradrenergic) with amitriptyline, attempted to answer the question as to whether such an agent possessed greater analgesia and effectiveness for PHN (16). Although amitriptyline was found to be more effective, nine patients responded equally well to both drugs and seven responded only to maprotiline. Thus, 16 of 32 patients $(50 \%)$ completing the trial may have had predominantly noradrenergic paininhibiting systems, whereas eight other responders required an agent with an effect on both serotonin and noradrenaline (amitriptyline). Patients reported that all three aspects of the pain of PHN responded to treatment, that is, steady pain, jabbing pain and pain on tactile skin contact. Side effects were troublesome with both agents, thus limiting their effectiveness. Again, most patients were not depressed, and pain relief occurred without a change in depression-rating scales. A recent trial has demonstrated that nortriptyline (noradrenergic) is equal to amitriptyline in relieving PHN and has fewer side effects (17). It was, therefore, concluded that the initial antidepressant of choice in PHN is amitriptyline or nortriptyline. If these fail, we recommend a selective noradrenergic agent such as desipramine or maprotiline.

There are no well designed, placebo controlled trials of a phenothiazine in the treatment of PHN. For the most part, the beneficial effects seen with the combination of an antidepressant and phenothiazine appear to be due to the antidepressant, the efficacy of which has been proved by controlled trials. Occasionally, patients have improved on different phenothiazines, but it is not clear whether the improvement was due to the drug, a placebo effect or a sedative effect, or was a result of the natural history of pain resolution.

Studies using the anticonvulsants carbamazepine, phenytoin and valproic acid for PHN have been either unimpressive or difficult to interpret because of the concomitant use of antidepressants (18-20). Although carbamazepine is a popular agent for treating paroxysmal lancinating pain, there is no conclusive evidence to justify its use in PHN, and clinical experience points to limited efficacy. Gabapentin has proved to be superior to placebo in $\mathrm{PHN}$, with $43 \%$ of patients reporting good or moderately good improvement (versus $12 \%$ with placebo) (21). Because of the apparent occurrence of fewer significant side effects with gabapentin than with antidepressant therapy, it has been suggested as a first-line treatment for this condition (21).

For a long time there has been a bias against using opioids for nonmalignant pain. There is now increasing support for the view that they are helpful and justifiable for selected patients (22-28). There are also uncontrolled observations suggesting that opioids relieve neuropathic pain. Uncontrolled data related to a long acting oral opioid (29) and single dose intravenous controlled trials (30-31) have supported the effectiveness of opioids in PHN. Our experiences with PHN have indicated that opioids are useful for some patients with this condition (14). Twenty-five of 90 patients with otherwise 
intractable pain achieved good to excellent results, and 50 others had $25 \%$ to $50 \%$ relief (14). A controlled trial of oxycodone in PHN has shown that $58 \%$ of patients experience at least moderately improved pain versus $18 \%$ with placebo (32). We continue to follow many postherpetic patients who are otherwise refractory to all the usual approaches. Often these patients receive renewed prescriptions for opioids, and patients rarely develop problems with tolerance or dependency. Usually, complete pain relief does not occur, which is similar to the effect of antidepressant therapy. Although opioids may reduce the severity of the pain, improvement is often modest; however, the improvement is often enough that patients choose to continue using these drugs. There appears to be a ceiling effect with opioids in PHN; below the ceiling some relief occurs, and above the ceiling no further pain relief occurs but side effects supervene to a point where dose escalation is refused.

A variety of short acting opioids are available for the treatment of PHN, including morphine, hydromorphone, anileridine, levorphanol, codeine and oxycodone. Sustainedrelease preparations also seem to be advantageous and include morphine, oxycodone, hydromorphone, and the fentanyl patch. Shorter acting agents may be used with these for rescue doses. Patients may respond better to one particular opioid than another, making a trial and error approach justifiable.

Intravenous lidocaine has been shown to relieve PHN (30). More practically, a lidocaine patch has proved to be superior to placebo in this condition $(33,34)$. Uncontrolled data suggest that topical acetylsalicylic acid in various vehicles may help this pain (35). Topical capsaicin has been difficult to study because blinding is impossible due to the burning induced by capsaicin (36). Our clinical experiences indicate that the effect of these agents are modest at best and that for most patients they are not useful as sole therapy.

For the truly intractable $30 \%$ of patients, the prevention of PHN by vaccination of the elderly and early aggressive treatment of acute zoster $(37,38)$ may limit inflammation and central neuronal hyperactivity. This prophylactic approach is almost entirely hypothetical, except for antiviral trials that indicate a modest effect at reducing PHN.

\section{PAINFUL DIABETIC NEUROPATHY}

PDN is common and comprises a number of diagnostic categories. Pharmacological approaches are based on a few clinical trials and clinical experience. It is not possible to tailor therapy to pain mechanisms. The role of diet, insulin and good diabetic control is important in the prevention and resolution of this pain.

As with PHN, considerable information about PDN comes from RCTs of antidepressants. Most of the evidence suggests that, of this group, the older antidepressants are most effective for relieving this type of neuropathic pain. Some early studies of antidepressants in PDN have been difficult to interpret because of the concomitant use of phenothiazines $(39,40)$. Turkington (41) found amitriptyline and imipramine to be superior to diazepam in a double-blind trial and thought relief accompanied amelioration of masked depression. Kvinesdal et al (42) found that imipramine was superior to placebo and commented that none of their patients were depressed, that pain relief was seen earlier and that blood levels were lower than those seen with an antidepressant. Max et al (43) found amitriptyline to be superior to active placebo in PDN. They observed that the drug produced relief of both the steady and the lancinating pain, that higher doses were associated with greater relief, and that relief occurred in depressed and nondepressed patients. Max et al (44) reported that desipramine (noradrenergic) was more effective than active placebo with this pain. Relief was greater in depressed patients, but improvement was also noted in nondepressed individuals. Another study by Max et al (45) found that desipramine provided relief similar to that provided by amitriptyline, both being superior to placebo, but that fluoxetine (serotonergic) showed no advantage. A trial of maprotiline (a noradrenergic antidepressant) found that it was effective in both diabetic and nondiabetic neuropathies (46), but less so than amitriptyline.

Single-blind (47) and double-blind (48) trials of imipramine (serotonergic and noradrenergic) have demonstrated its superiority to placebo. Imipramine was also found to be superior to mianserin (5-hydroxytriptamine antagonist, noradrenergic) by RCT in this disorder (49). From these studies, it appears that antidepressants, with an effect on both serotonin and noradrenaline and more selective noradrenergic agents, are effective for some patients with PDN. These results are similar to those found with PHN.

Other trials, both single-blind (50) and double-blind (51), have shown an effect from the serotonergic antidepressant, paroxetine. RCTs have found the serotonergic antidepressant clomipramine, to be superior to desipramine (noradrenergic) (52) and the serotonergic drug citalopram (53) to be superior to placebo in this type of neuropathic pain. These latter trials differ from research in PHN in that they indicate an effect from serotonergic agents in PDN that has not been shown in PHN.

The anticonvulstant carbamazepine has been reported to be effective in two double-blind, placebo controlled trials $(54,55)$. A large placebo effect was present in both studies, and it is difficult to know how effective the drug was in producing satisfactory relief. A carbamazepine open-label trial of 54 patients indicated complete relief in 44 (56). Two controlled trials of phenytoin have produced conflicting results $(57,58)$. An open-label trial of phenytoin found that $68 \%$ of 60 patients had excellent results (59). Uncontrolled observations suggested to one author that clonazepam was useful for some patients (60). Gabapentin has recently been shown to be superior to placebo in an RCT, with $60 \%$ of patients having at least moderate improvement (versus 33\% with placebo) (61). Because it has fewer side effects than antidepressants, it has been suggested as a first-line therapy.

Mexiletine is an oral local anesthetic-like drug, that has been effective in one small RCT of PDN at higher doses (62) but not effective in the range of 225 to $675 \mathrm{mg}$ daily seen in another study (63). 
There are no controlled trials of opioids for treating this condition. Tramadol is a centrally acting analgesic with an effect on opioid receptors and also on the reuptake of noradrenaline and serotonin. This agent was found to be effective in PDN by RCT (64).

A number of studies have examined the use of topical capsaicin in PDN (36). These have been very difficult to appraise because of a large placebo effect and the impossibility of blinding due to the burning induced by capsaicin.

\section{OTHER PERIPHERAL NEUROPATHIC PAIN}

Well controlled trials do not exist for the variety of other peripheral neuropathic pains listed in Table 1 (excluding trigeminal neuralgia). Topical capsaicin may be useful for some patients with the incisional neuralgia called postmastectomy pain syndrome (36), but the trials have been impossible to blind satisfactorily. Although Mitchell (1) recognized that opioids relieved causalgia at the time of the American Civil War, their abuse and overuse led to the opioid phobia that has been such a hindrance for so long.

\section{CENTRAL PAIN}

Some of the various central painful states are listed in Table 2. There is little scientific or good anecdotal information therapeutically about most of these individual conditions.

A three-phase, placebo controlled trial of amitriptyline and carbamazepine in patients with central poststroke pain demonstrated a statistically significant reduction in pain with amitriptyline (65). Another RCT found no effect of trazodone (a serotonin potentiating antidepressant) in spinal cord injury pain (66). Desipramine trials have shown that this noradrenaline-potentiating antidepressant may relieve central pain (67). These results are of interest because they parallel the research discussed already in the peripheral neuropathic pain disorders of PHN and PDN. Carbamazepine appears to be effective for trigeminal neuralgia, painful tonic seizures and other central pain due to multiple sclerosis, based on clinical experience and uncontrolled published observations. No controlled trials exist for anticonvulsants or opioids in central pain. A widespread belief exists that this type of pain is opioid-resistant. This perception may, however, be generated in part by the fear of these agents and, hence, a hesitancy to use them to their full potential.

\section{DISCUSSION}

Much of the clinical research with antidepressants in PHN and PDN has produced similar results. That is, the older, less selective antidepressants seem to be most effective. Noradrenergic agents, although useful, may have a weaker analgesic action. The more selective serotonergic agents appear to be ineffective or much less effective for most patients with PHN but may be of greater value in PDN. Reasons for this apparent difference in the effect of serotonergic drugs between the two disorders may be differences in pain mechanisms or the lack of similar studies in PHN. The serotonergic studies in PDN are also small in number, and it is difficult to determine the clinical effectiveness of the drugs because a statistical difference in efficacy may not translate into good relief and patient satisfaction. The trials of antidepressants in central pain, although few, tend to support those in peripheral neuropathic pain. These findings are in keeping with those of a recent systematic review of antidepressants in neuropathic pain (68). The anticonvulsant gabapentin may be useful for neuropathic pain and appears to have fewer side effects than antidepressants. Carbamazepine may be useful for some cases of PDN, for trigeminal neuralgia (the drug of choice) and for pain syndromes in multiple sclerosis (69).

\section{Practical therapeutic guidelines}

From the preceding discussion it is clear that for many specific types of neuropathic pain there is limited scientific information to guide the clinician. The following recommendations are, in part, based on clinical experience as well as what is known from the RCTs in PHN and PDN. These findings provide a reasonable basis for general guidelines that may be applied to any such pain, until more specific data are available on individual pain mechanisms and new therapies.

Antidepressant Therapy: Although an argument has been put forth for gabapentin $(21,61)$, it is not known how it compares with the standard therapy, the older antidepressants. It is our belief that the first-line therapy for most neuropathic pain should be amitriptyline or nortriptyline. The latter may be preferable because it has fewer side effects (17). The median dose that relieves this pain in some trials is 50 to $75 \mathrm{mg}$; however, the dose may vary widely. Because of this variability and because side effects are problematic with the older antidepressants, it is suggested that treatment start with a low dose. In patients less than 65 years of age a starting dose of 25 $\mathrm{mg}$ is suggested, and with those older than 65 years of age, 10 $\mathrm{mg}$. It is prudent to prescribe pre-emptively a stool softener such as docusate sodium and a mouth spray to deal with constipation and dry mouth, respectively. Patients should be cautioned about the possibility of other important side effects such as drowsiness, weight gain and, in the older male, urinary retention. These drugs may be given in a single bedtime dose. Every seven to 10 days the dose can be increased by 10 to 25 $\mathrm{mg}$ until satisfactory pain relief occurs or unacceptable side effects supervene. Blood levels are only of use as a guide to compliance and to substantiate the clinical impression (eg, lack of a dry mouth) that a further increase is possible. The presence of a dry mouth may be a good indication that the drug is reaching a significant level in the blood. There is no therapeutic range of blood levels for pain relief. The final dose may be as little as $5 \mathrm{mg}$ or more than $200 \mathrm{mg}$. If amitriptyline and nortriptyline fail, it is worth trying a more noradrenergic agent such as desipramine or maprotiline using a similar dosing escalation schedule. Antidepressant therapy commonly reduces the pain from moderate or severe to mild in one-half to two-thirds of patients, with complete relief being unusual. Side effects often have to be accepted if they are tolerable or manageable. In diabetic neuropathy, there is evidence that imipramine as well as the serotonergic agents clomipramine and paroxetine may be effective. 
Anticonvulsants: Anticonvulsants may be useful if antidepressants fail. Gabapentin may become a first-line agent for neuropathic pain. It is so recommended by some authors $(21,61)$ because there appear to be fewer side effects than with other therapies and efficacy is thought to be comparable. Doses of up to $3600 \mathrm{mg} /$ day have been suggested. Carbamazepine may be considered first-line treatment for trigeminal neuralgia and for the various pain syndromes of multiple sclerosis such as painful tonic seizures. This drug may be started at a dose of $100 \mathrm{mg}$ two to three times per day. The dose can be increased after a week or two to $200 \mathrm{mg}$ two to three times per day and thereafter to a level that produces pain relief or drowsiness or other side effects as an end point. Drug levels in the blood may be a guide to compliance and dose escalation. Sustained-release preparations can be particularly useful to improve tolerability and compliance. Phenytoin may be initiated at a dose of $100 \mathrm{mg}$ daily at bedtime for the elderly patient or $300 \mathrm{mg}$ daily at bedtime for a younger patient with blood levels used as a guide to dose increases and compliance, and titration to pain relief or side effects. Other potentially useful anticonvulsants are clonazepam and valproic acid, using the guidelines available in any pharmacological reference source. Whether the combination of an antidepressant with an anticonvulsant such as gabapentin is useful is not clear, but this may be considered for difficult cases where pain is incompletely relieved by one agent.

Opioids: The use of opioids for neuropathic pain when all else has failed remains contentious but has growing support from both clinical trials and survey data. Clinical experience indicates that when these drugs are used for pain, the risk of psychological dependence (addiction) is low, and problems with physical dependence and tolerance do not occur in most patients. It is important to know this because opioids may be the only avenue of relief for many patients with severe neuropathic pain. Complete relief is unusual, and the aim is to make pain more tolerable and to improve quality of life. It is advisable to follow certain guidelines if opioids are used. This is good medical practice but also protects the clinician in the face of scrutiny by regulatory bodies. The following guidelines are suggested.

Use a single prescriber

Use a single pharmacy

Schedule regular visits (every one to three months) and document the drug, the strength and number of pills prescribed and the clinical status (pain levels with and without the drug used, quality of life and side effects)

Attach a copy of the prescription to the chart (either carbon impression or photocopy), at the patient visit note site

Create a flow sheet showing drug, strength and number of pills prescribed at each visit

Avoid prescribing for patients with a history of chemical dependency (there are exceptions to this rule)

\section{Cease therapy if drug-seeking behaviour occurs}

Solicit written testimonials from significant others to as to the treatment benefits,be incorporated in the chart.

Other guidelines are also available (70-74).

It is worth trying another opioid if the first one fails because one may be more effective than another for an individual patient or type of neuropathic pain. Short acting opioids include codeine, morphine, oxycodone, hydromorphone and anileridine. The dose may be slowly increased every few days depending on response, side effects and drug pharmacokinetics. It is reasonable to prescribe an antinauseant and a stool softener, particularly in a patient using opioids for the first time. Once a response is achieved with a short acting opioid a switch can be made to a longer acting opioid such as sustained-release morphine, which may be more convenient, have fewer side effects and be more effective for chronic pain. Short acting opioids may still be necessary for acute episodes. Other sustained-release preparations are available such as sustained-release oxycodone, hydromorphone and a skin patch for fentanyl. Methadone usage requires special knowledge as well as a special license and in our view should be at least initiated by those sophisticated in its use. Our patients often report that although they obtain increasing relief with increasing doses of an opioid, a ceiling is reached beyond which only more side effects are encountered so that escalation beyond that point does not occur. Opioids may be combined with antidepressant or anticonvulsant therapy. It may be useful to begin with a low dose of antidepressant at bedtime and provide intermittent doses of a short acting opioid. At subsequent visits, the dose of antidepressant can be increased as suggested above, and at the same time the clinician can evaluate the effectiveness of the opioid. It is important to use very small initial doses of any of these agents with the elderly. Also, with a patient of any age, the maxim of 'start low and go slow' is a good one, and for patients who appear to be sensitive to drugs, monotherapy at therapy initiation is prudent.

Topical agents: The topical agents that have been studied most frequently for neuropathic pain are capsaicin and nonsteroidal anti-inflammatory drugs (NSAIDs), particularly acetylsalicylic acid and local anesthetics. The use of topical agents under an commercially available occlusive dressing or plastic food wrap, may provide greater efficacy but can often also cause skin irritation. A topical lidocaine skin patch may be particularly valuable (34).

Capsaicin is the active ingredient in red peppers and other pepper plants and is thought to act by depleting substance $\mathrm{P}$ and other peptides in small primary afferents (36). It needs to be applied repeatedly (three to four times daily) over three weeks. A strong burning sensation induced by this compound during initial treatment may be intolerable. Capsaicin has been impossible to study in controlled trials because of the burning sensation. Acetylsalicylic acid is usually crushed (eg, two tablets) and mixed in a vehicle (30 mls of ether or chloroform or Vaseline intensive care lotion (Unilever, New 
York) and applied to the painful hyperesthetic skin as needed. Topical ether and chloroform must, of course, be used carefully, particularly in elderly patients. Local anesthetics such as lidocaine (33-35) or a eutectic mixture of local anesthetics (AstraZeneca, Mississauga, Ontario) may also be applied as needed. In our experience, topical approaches are rarely useful as sole therapy except in the occasional patient but may be a useful adjunct to other therapeutic agents.

\section{Miscellaneous treatments}

For patients who are desperate there are a variety of trial and error approaches, none of which is scientifically secure. Although they do not help most patients, they are worth trying because occasionally individuals appear to respond. Also discussed here are treatments that have been studied and appear to be of little use such as the $N$-methyl-D-aspartate (NMDA) inhibitors now available.

Serotonin reuptake inhibitors: The newest family of antidepressants, serotonin uptake inhibitors, do not appear to have good pain relieving properties. Some patients, however, say they feel better or cope better with the pain while taking these drugs. Some of the choices in this drug class are fluoxetine, fluvoxamine, sertraline and paroxetine. In our clinical experience, doses of fluoxetine in the range of 40 to $60 \mathrm{mg}$ may be more effective than $20 \mathrm{mg}$, if tolerated.

Clonidine: Clonidine has been studied in PDN $(75,76)$ and in PHN (77) but does not appear to be of practical use.

Mexiletine and lidocaine: The orally active local anesthetic agents mexiletine and lidocaine seem to improve chronic neuropathic pain in some patients $(78,79)$. Doses range from 225 to $750 \mathrm{mg}$ in controlled trials, and higher doses may be more effective. Blood level measurements for this drug do not seem to be of practical value, and caution should be exercised in administering mexiletine with antidepressants.

Baclofen: Baclofen can be used alone for trigeminal neuralgia or in conjunction with carbamazepine. However, its use for other neuropathies has not been demonstrated by RCTs. Our clinical experience indicates that it does not provide good results for most patients. Reasonable doses range from 10 to $20 \mathrm{mg}$ three times per day.

Acetaminophen and NSAIDs: Acetaminophen and NSAIDs usually are not useful for neuropathic pain $(77,80)$, but occasionally patients may find them beneficial. Acetaminophen should be used with caution because of the potential for hepatotoxicity with chronic use. If used, regular liver function tests are recommended, and doses should be limited to less than 2000 to $4000 \mathrm{mg} /$ day. If acetaminophen with codeine or oxycodone is used it is prudent to try to switch to the opioid alone. Responses to NSAIDs in chronic pain may be idiosyncratic; therefore, trials of different categories of agents may be warranted. Enteric-coated preparations of acetylsalicylic acid and naproxen, or diclofenac combined with misoprostol (Arthrotec, Searle Canada, Mississauga, Ontario) are of possible use in reducing gastrointestinal upset. Cyclo-oxygenase-II (COX-2) inhibitors are now available. These do not have the side effects of other available NSAIDs and may prove to be useful.
NMDA antagonists: The available NMDA antagonists are ketamine and dextromethorphan. Parenteral ketamine has been effective in PHN $(81,82)$. High doses of dextromethorphan in an RCT have demonstrated an effect in PDN (83). However, because of side effects and limited efficacy, NMDA antagonists cannot be regarded as practical, at this time, for these conditions.

Transcutaneous electrical nerve stimulation, acupuncture and relaxation therapy: There are many nonpharmacological approaches for the treatment of neuropathic pain. In our view, anything that is safe and reasonably economical is worth a try in truly desperate patients. However, referral of these patients for behaviour modification therapy, without initiation or continuation of pharmacological approaches, in the presence of a clear history and with signs of neuropathic pain, is naive and callous.

Nerve blocks: Regional anesthesia (nerve block therapy) has a long history and is widely used for neuropathic pain, particularly complex regional pain syndrome. Although there is scant good science to support using this therapy for peripheral neuropathic pain, a trial in competent hands is reasonable in refractory patients. Relief with this approach does not predict relief by surgical deafferentation.

Surgery: The only neuropathic pain problem responding well to surgery is trigeminal neuralgia. Surgical deafferentation for other nerve injury is usually not useful and may aggravate the condition. Stimulation procedures (dorsal column and deep brain stimulation) may be of use in selected intractable patients, but initial surgical success is about $50 \%$ at best.

\section{Prevention of neuropathic pain}

There is evidence that acute severe pain (eg, the severing of a nerve during surgery under general anesthesia or acute HZ) may create a state of central neuronal hyperexcitability that may provide the substrate for persistent pain. It is possible that this may be prevented during surgery by pre-emptive local anesthetic blockade and perioperative opioids (84). Preemptive treatment is, however, not possible for nonsurgical acute pain such as HZ, but for this condition, early aggressive relief of the acute pain may prevent the transition to PHN (38). Examples of this type of aggressive relief include nerve blocks, antiviral agents, early antidepressant therapy and prompt treatment with adequate analgesics and opioids if required. The efficacy of most of these methods has not yet been proven, but they appear to be reasonable and safe. The advent of the varicella vaccination is another approach that, when available for the elderly patient, may prevent $\mathrm{HZ}$ and, hence, postherpetic pain. Better diabetic control may contribute to a reduction in long term complications such as painful neuropathies. Protection of the nerves during operations such as thoracotomy and careful dissection may minimize nerve trauma and reduce the incidence and severity of post-thoracotomy pain and other incisional neuralgias.

\section{CONCLUSIONS}

Steady but slow progress has been made in clarifying the effective treatment of neuropathic pain. It is possible to provide satisfactory relief for more than half of the sufferers of these 
conditions. Spontaneous improvement may also occur over time even with long standing pain. Better therapies are needed. Research in PHN, PDN and central pain, with regard to antidepressant therapy, is similar, that is, some of the older antidepressants appear to be most effective. Possible differences are that some serotonergic antidepressants and some anticonvulsants may be more effective in PDN and that the NMDA antagonist dextromethorphan appears to have a weak effect in PDN but not PHN. Pre-emptive approaches and early aggressive treatment of acute pain may be useful in preventing progression to a chronic painful state.

\section{REFERENCES}

1. Mitchell SW. Injuries of Nerves and Their Consequences. New York: JB Lippincott, 1872:270.

2. Merskey H, Bogduk N. Classification of Chronic Pain. Descriptions of Chronic Pain Syndromes and Definition of Pain Terms, 2nd edn. Seattle: IASP Press, 1994.

3. Kingery W. A critical review of controlled clinical trials for peripheral neuropathic pain and complex regional pain syndromes. Pain 1997;73:123-39.

4. Begg C, Cho M, Eastwood S, et al. Improving the quality of reporting of randomized controlled trials. The CONSORT Statement. JAMA 1996;276:637-63.

5. Kurtzke JF. Neuroepidemiology. Ann Neurol 1984;16:265-77.

6. Watson CPN. Postherpetic neuralgia: a review. Arch Neurol 1986;43:836-40.

7. Watson CPN. Postherpetic neuralgia: an end stage, intractable disorder and the importance of prevention. J Infect Dis 1998;178 (Suppl 1):S91-4.

8. Woodforde JM, Dwyer B, McEwen BW, et al. The treatment of postherpetic neuralgia. Med J Aust 1965;2:869-72.

9. Taub A. Relief of postherpetic neuralgia with psychotropic drugs. J Neurosurg 1973;39:235-9.

10. Taub A, Collins WF. Observations on the treatment of denervation dysesthesia with psychotropic drugs. Adv Neurol 1974:4:309-15.

11. Watson CPN, Evans RJ, Reed K, Merskey H, Goldsmith L, Warsh J. Amitriptyline versus placebo in postherpetic neuralgia. Neurology 1982;32:671-3.

12. Max MB, Schafer SC, Culnane M, Smoller B, Dubner R, Gracely RH. Amitriptyline but not lorazepam relieves postherpetic neuralgia. Neurology 1988;38:1427-32.

13. Watson CPN, Evans RJ. A comparative trial of amitriptyline and zimelidine in postherpetic neuralgia. Pain 1985;23:387-94.

14. Watson CPN, Evans RJ, Watt VR, Birkett N. Postherpetic neuralgia: 208 cases. Pain 1988;35:289-9.

15. Kishore-Kumar R, Max MB, Schafer SC, et al. Desipramine relieves postherpetic neuralgia. Clin Pharmacol Ther 1990;47:305-12.

16. Watson CPN, Chipman M, Reed K, Evans RJ, Birkett N. Amitriptyline versus maprotiline in postherpetic neuralgia: A randomized double-blind crossover trial. Pain 1992;48:298-36.

17. Watson CPN, Vernich L, Chipman M, Reed K. Amitriptyline versus nortriptyline in postherpetic neuralgia. Neurology 1998;51:1166-71.

18. Hatangdi VS, Boad RA, Richards EG. Postherpetic neuralgia: Management with anti-epileptic and tricyclic drugs. In: Bonica JJ, Albe-Fessard D, eds. Advances in Pain Research and Therapy. New York: Raven Press 1976;1:583-7.

19. Killian JM, Fromm GH. Carbamazepine in the treatment of neuralgia. Arch Neurol 1968;19:129-36.

20. Raftery $H$. The management of postherpetic neuralgia using valproate and amitriptyline. Irish Med J 1979;72:399-401.

21. Rowbotham M, Harden N, Stacey B, et al. Gabapentin for the treatment of postherpetic neuralgia: a randomized controlled trial. JAMA 1998;280:1837-42.
22. France RD, Urban BJ, Keefe FJ. Long-term use of narcotic analgesics in chronic pain. Soc Sci Med 1984;19:1379-82.

23. Portenoy RK, Foley KM. Chronic use of opioid analgesics in non-malignant pain: report of 38 cases. Pain 1986;25:171-86.

24. Urban BJ, France RD, Steinberger DL, Scott DL, Maltbie AA. Long-term use of narcotic-antidepressant medication in the management of phantom limb pain. Pain 1986;24:191-7.

25. Galer BS, Coyle N, Pasternak GW, Portenoy RK. Individual variability in the response to different opioids: report of five cases. Pain 1992;49:87-91.

26. Mercadante S, Maddaloni S, Roccella S, Salvaggio L. Predictive factors in advanced cancer pain trated only by analgesics. Pain 1992;50:151-5.

27. Zenz M, Strumpf M, Tryba M. Long-term opioid therapy in patients with chronic nonmalignant pain. J Pain Symptom Manage 1992;7:89-97.

28. Portenoy RK. Opioid therapy for chronic nonmalignant pain. Pain Res Manage 1996;1:17-28.

29. Pappagallo M, Campbell JN. Chronic opioid therapy as alternative treatment for postherpetic neuralgia. Ann Neurol 1994;35:S54-6.

30. Rowbotham MC, Reisner-Keller IA, Fields HL. Both intravenous lidocaine and morphine reduce the pain of postherpetic neuralgia. Neurology 1991;41:1024-8.

31. Dellemijn PL, Vanneste JA. Randomized double-blind active placebo-controlled crossover trial of intravenous fentany in neuropathic pain. Lancet 1997;349:753-8.

32. Watson CPN, Babul N. Oxycodone relieves neuropathic pain: a randomized trial on postherpetic neuralgia. Neurology 1998;50:1837-41.

33. Rowbotham MC, Davies PS, Fields HL. Topical lidocaine gel relieves postherpetic neuralgia. Ann Neurol 1995;37:246-53.

34. Rowbotham MC, Davies PS, Verkempinck C, Gater BS. Lidocaine patch: double-blind controlled study of new treatment method for postherpetic neuralgia. Pain 1996;65:39-44.

35. Rowbotham MD. Topical agents for postherpetic neuralgia. In: Watson CPN, ed. Herpes Zoster and Postherpetic Neuralgia. New York: Elsevier, 1993.

36. Watson CPN. Topical capsaicin as an adjuvant analgesic. J Pain Symptom Manage 1994;9:425-33.

37. Bowsher D. The effects of pre-emptive treatment of postherpetic neuralgia by amitriptyline: a randomized, double-blind, controlled trial. J Pain Symptom Manage 1998;13:327-31.

38. Watson CPN, Postherpetic neuralgia: prevention of an end-stage intractable disorder. J Infect Dis 1998;178 (Suppl 1):S91-4.

39. Davis JL, Lewis SB, Erich JE, et al. Peripheral diabetic neuropathy treated with amitriptyline and fluphenazine. JAMA 1977:238:2291-2.

40. Gomez-Perez FJ, Rull JA, Dies H, Rodrigues-Rivera JG, Gonzalez-Barranco J, Lozano-Casteneda O. Nortriptyline and fluphenazine in the symptomatic treatment of diabetic neuropathy: a double-blind study. Pain 1985;23:395-400.

41. Turkington RW. Depression masquerading as diabetic neuropathy. JAMA 1980;243:1147-50.

42. Kvinesdal B, Molin J, Froland A, Gram LF. Imipramine treatment of painful diabetic neuropathy. JAMA 1984;251:1727-30.

43. Max MB, Culnane M, Schafer SC, et al. Amitriptyline relieves diabetic neuropathy pain in patients with normal or depressed mood. Neurology 1987;37:589-96.

44. Max MB, Kishore-Kumar R, Schafer SC, et al. Efficacy of desipramine in painful diabetic neuropathy: A placebo-controlled trial. Pain 1991;45:3-9.

45. Max MB, Lynch SA, Muir J, et al. Effects of desipramine, amitriptyline, and fluoxetine on pain in diabetic neuropathy. N Engl $\mathrm{J}$ Med 1992;326:1250-6.

46. Vrethem M, Boivie J, Arnqvist H, et al. A comparison of amitriptyline and maprotiline in the treatment of painful diabetic neuropathy in diabetics and nondiabetics. Clin J Pain 1997;13:313-23.

47. Sindrup SH, Gram LF, Skjold T, Froland A, Beck-Nielsen H. 
Concentration-response relationship in imipramine treatment of diabetic neuropathy symptoms. Clin Pharmacol Ther 1990;47:509-15.

48. Sindrup SH, Ejlertsen B, Froland A, Sindrup EH, Brosen K, Grant LF. Imipramine treatment in diabetic neuropathy: relief of subjective symptoms without changes in peripheral and autonomic nerve function. Eur J Clin Pharmacol 1989;37:151-3.

49. Sindrup SH, Tuxen C, Gram LF, et al. The effect of mianserin on the symptoms of diabetic neuropathy. Eur J Clin Pharmacol 1992;43:251-5.

50. Sindrup SH, Grodum B, Gram LF, Beck-Nielsen H. Concentrationresponse relationship in paroxetine treatment of diabetic neuropathy symptoms: a patient-blinded dose-escalation study. Ther Drug Monit 1991;13:408-14.

51. Sindrup SH, Gram LF, Brosen K, Eshoj O, Mogensen EF. The selective serotonin reuptake inhibitor paroxetine is effective in the treatment of diabetic neuropathy symptoms. Pain 1990;42:135-44.

52. Sindrup SH, Gram LV, Skjold T, Grodum E, Brosen K, Beck-Nielson H. Clomipramine vs desipramine vs placebo in the treatment of diabetic neuropathy symptoms. A double-blind cross-over study. Br J Clin Pharmacol 1990;30:683-91.

53. Sindrup SH, Bjerre U, Dejgaard A, Brosen K, Aaes-Jorgenson T, Gram LF. The selective serotonin reuptake inhibitor citalopram relieves the symptoms of diabetic neuropathy. Clin Pharmacol Ther 1992;52:547-52.

54. Rull JA, Quibrera R, Gonzalez-Millan H. Castaneda OL. Symptomatic treatment of peripheral diabetic neuropathy with carbamazepine (Tegretol): Double-blind crossover trial. Diabetologia 1969;5:215-8.

55. Wilton TD. Tegretol in the treatment of diabetic neuropathy. S Afr Med J 1974;48:869-72.

56. Chakrabartl AK, Samantary SK. Diabetic peripheral neuropathy: Nerve conduction studies before, during and after carbamazepine therapy. Aust NZ Med J 1976;6:565.

57. Chadda VS, Mathur MS. Double-blind study of the effects of diphenylhydantoin sodium on diabetic neuropathy. J Assoc Physicians India 1978;26:403-6.

58. Saudek CD, Werns S, Reidenberg MM. Phenytoin in the treatment of diabetic symmetrical polyneuropathy. Clin Pharmacol Ther 1977;22:196-9.

59. Ellenberg M. Treatment of diabetic neuropathy with diphenylhydantoin. NY State Med J 1968;68:2653-5.

60. Swerdlow M, Cundill JG. Anticonvulsant drugs used in the treatment of lancinating pain: A comparison. Anaesthesia 1981;36:1129-32.

61. Backonja M, Beydoun A, Edwards KK, et al. Gabapentin for the symptomatic treatment of painful neuropathy in patients with diabetes mellitus. JAMA 1998;280:1831-7.

62. Dejgard A, Petersen P, Kastrup J. Mexiletine for treatment of chronic painful diabetic neuropathy. Lancet 1988;i:9-11.

63. Stracke H, Meyer U, Schumacher HE, et al. Mexiletine in the treatment of diabetic neuropathy. Diabetes Care 1992;15:1550-5.

64. Harati Y, Gooch C, Swenson MD, et al. Double-blind randomized trial of tramadol for the pain of diabetic neuropathy. Neurology 1998;50:1842-6

65. Leijon O, Boivie J. Central post-stroke pain - a controlled trial of amitriptyline and carbamazepine. Pain 1989;36:27-36.

66. Davidoff G, Guarrinci M, Roth E, et al. Trazodone hydrochloride in the treatment of dysesthetic pain in traumatic myelopathy: A randomized, double-blind, placebo-controlled study. Pain 1987;29:151-61

67. Leijon G, Boivie J. Pharmacological treatment of central pain. In: Casey KL, ed. Pain and Central Nervous System Disease. New York: Raven, 1991:257-66.

68. McQuay HJ, Tramer M, Nye BA, et al. A systematic review of antidepressants in neuropathic pain. Pain 1996;68:217-27.
69. McQuay HJ, Carroll D, Madad AR. Anticonvulsant drugs for management of pain: a systemic review. BMJ 1995;311:1047-52.

70. Goldman B, Gayle G, Gilchrist G, Jacobs H, Kerr I, Rothbart P. Use of opioids for the treatment of chronic pain of nonmalignant origin. Pain Res Manage 1997;2:231-5.

71. Hagen N, Flynne P, Hays H, et al. Guidelines for managing chronic non-malignant pain: Opioids and other agents. Can Fam Physician 1995;41:49-53.

72. Moulin D. Opioid analgesics for chronic nonmalignant pain. Can J Cont Med Educ 1996;8:137-144.

73. Portenoy R. Opioid therapy for chronic nonmalignant pain. Pain Res Manage 1996;1:17-28.

74. Use of opioid analgesics for the treatment of chronic non-malignant pain - A consensus statement and guidelines from the Canadian Pain Society. Pain Res Manage 1998;3:197-20-8.

75. Zeigler D, Lynch SA, Muir J, Benjamin J, Max MB. Transdermal clonidine versus placebo in painful diabetic neuropathy. Pain 1992;48:403-8.

76. Byas-Smith MG, Max MB, Muir J, Kingman A. Transdermal clonidine compared to placebo in painful diabetic neuropathy using a two-stage 'enriched enrollment' design. Pain 1995;60:267-74.

77. Max MB, Schafer SC, Culnane M, Dubner R, Gracely RH. Association of pain relief with drug side effects in postherpetic neuralgia: a single dose study of clonidine, codeine, ibuprofen, and placebo. Clin Pharmacol Ther 1998;43:1427-32.

78. Dejgard A, Petersen P, Kastrup J. Mexiletine for treatment of chronic painful diabetic neuropathy. Lancet 1988;ii:9-11.

79. Stracke H, Meyer U, Schumacher HE, et al. Mexiletine in the treatment of diabetic neuropathy. Diabetes Care 1992;15:1550-5.

80. Cohen KL, Harris S. Efficacy and safety of non-steroidal anti-inflammatory drugs in the therapy of diabetic neuropathy. Arch Intern Med 1987;147:1442-4.

81. Eide PK, Stubbaug A, Oye I, Breivik H. Continuous subcutaneous administration of the $N$-methyl-D-aspartic acid (NMDA) receptor antagonist ketamine in the treatment of post-herpetic neuralgia. Pain 1995;61:221-8.

82. Eide PK, Jorum E, Stubbaug A, Bremnes J, Breivik H. Relief of post-herpetic neuralgia with the $N$-methyl-D-aspartic acid receptor antagonist ketamine: a double-blind,-cross-over comparison with morphine and placebo. Pain 1994;58:347-54.

83. Nelson KA, Park KM, Robinovitz E, et al. High dose oral dextromethorphan versus placebo in painful diabetic neuropathy and postherpetic neuralgia. Neurology 1997;48:1212-8.

84. Katz J. Pre-emptive analgesia: evidence, current status and future directions. Eur J Anaesthesiol 1995;12 (Suppl 10):8-13.

85. Kastrup J, Petersen P, Dejgard A, Angelo HR, Hilsted J. Intravenous lidocaine infusion - a new treatment for painful diabetic neuropathy. Pain 1987;28:69-75.

86. Bernstein JE, Korman NE, Bicker DR, Dahl MV, Millikan LE. Topical capsaicin treatment of postherpetic neuralgia. J Am Acad Dermatol 1989;21:265-70.

87. Capsaicin Study Group. Treatment of painful diabetic neuropathy with topical capsaicin, a multicenter, double-blind, vehicle-controlled study. Arch Intern Med 1991;151:2225-9.

88. Chad DA, Aronin N, Lundstrom R, et al. Does capsaicin relieve the pain of diabetic neuropathy? Pain 1990;42:387-8.

89. Benedettis GD, Besana F, Lorenzetti A. A new topical treatment for acute herpetic neuralgia and post-herpetic neuralgia: the aspirin diethyl ether mixture. An open-label study plus a double-blind controlled clinical trial. Pain 1992;48:383-90.

90. Benedettis GD, Lorenzetti A. Topical aspirin/diethyl ether mixture versus indomethacin and diclofenac/diethyl ether mixture for acute herpetic neuralgia and postherpetic neuralgia: a double-blind crossover placebo-controlled study. Pain 1996;65:45-51. 


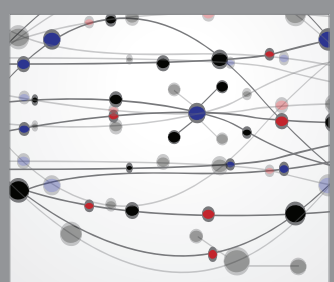

The Scientific World Journal
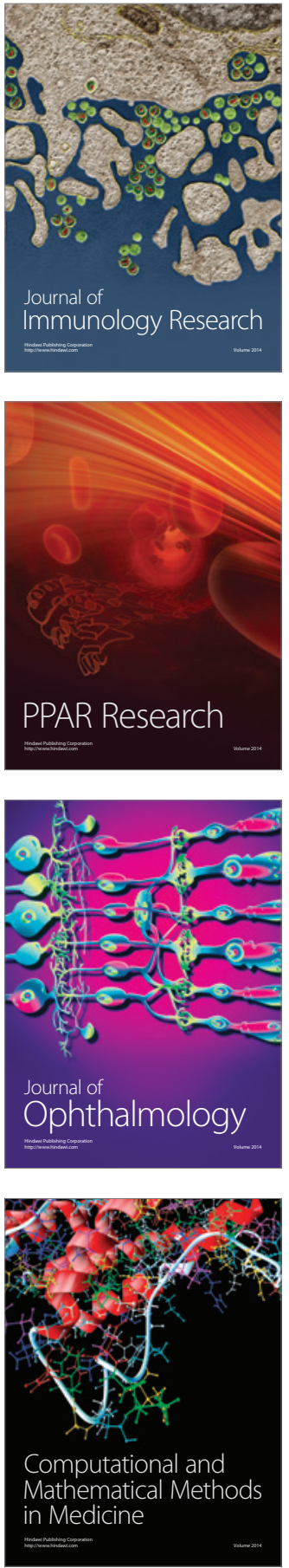

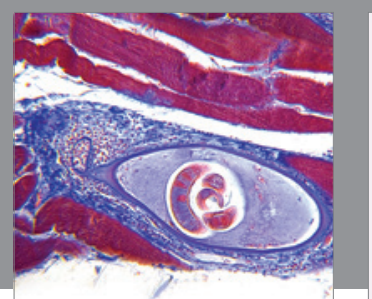

Gastroenterology Research and Practice

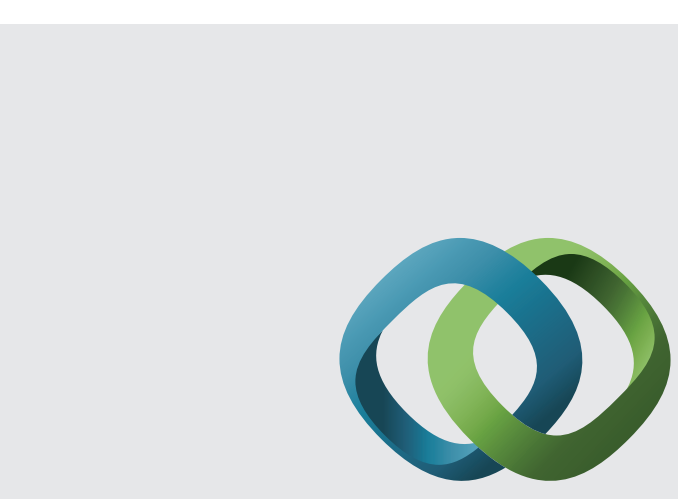

\section{Hindawi}

Submit your manuscripts at

http://www.hindawi.com
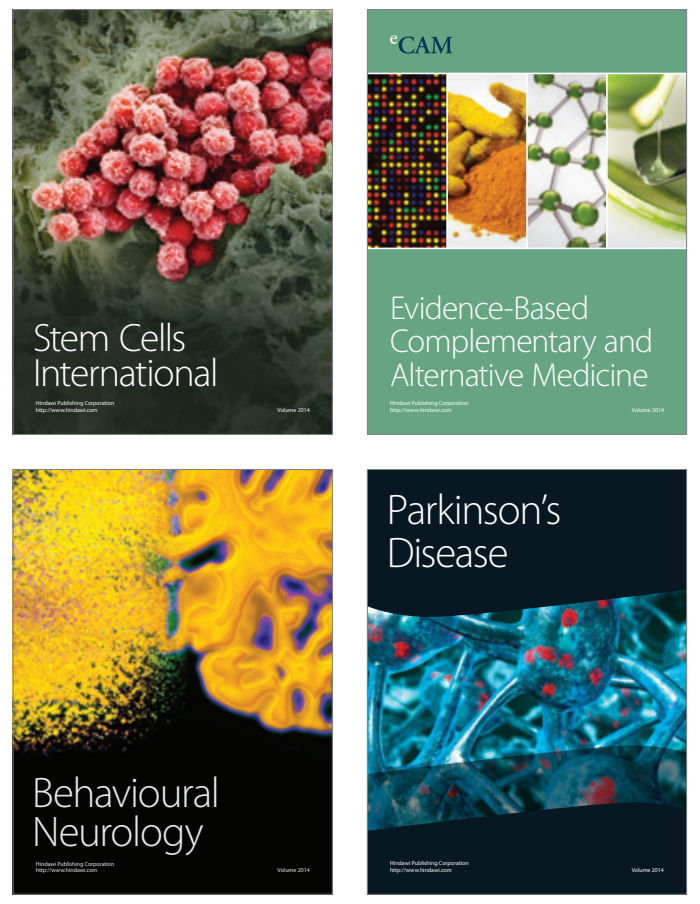
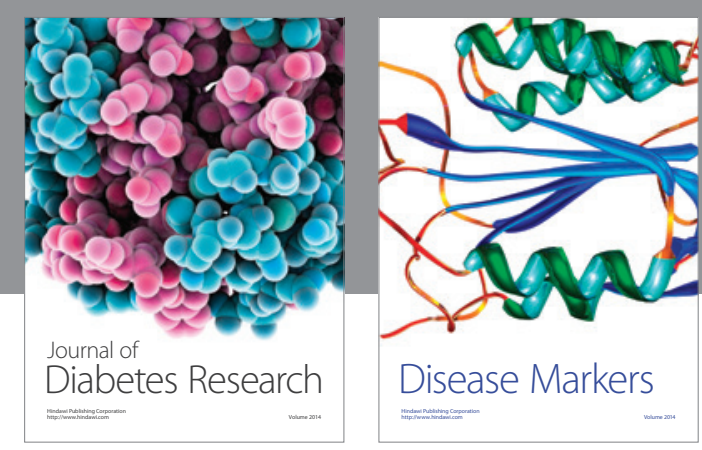

Disease Markers
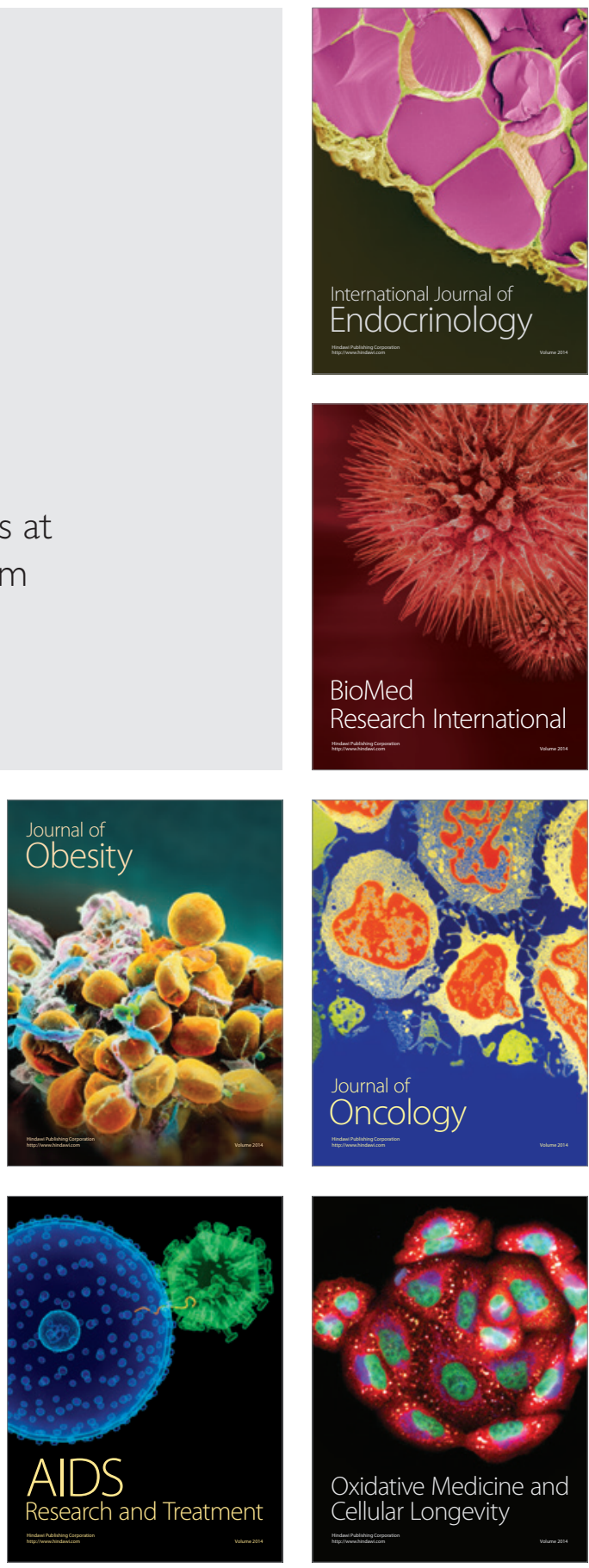